\title{
Application of ambient ionization high resolution mass spectrometry to determination of the botanical provenance of the constituents of psychoactive drug mixtures.
}

\author{
Ashton D. Lesiak ${ }^{1}$ and Rabi A. Musah ${ }^{1^{*}}$ \\ ${ }^{1}$ Department of Chemistry, University at Albany-State University of New York, 1400 Washington \\ Ave, Albany, NY 12222 \\ *Corresponding author: E-mail address: rmusah@albany.edu
}

Fax: $518-442-3462$ 


\section{ABSTRACT}

A continuing challenge in analytical chemistry is species-level determination of the constituents of mixtures that are made of a combination of plant species. There is an added urgency to identify components in botanical mixtures that have mind altering properties, due to the increasing global abuse of combinations of such plants. Here we demonstrate the proof of principle that ambient ionization mass spectrometry, namely direct analysis in real time-high resolution mass spectrometry (DART-HRMS), and statistical analysis tools can be used to rapidly determine the individual components within a psychoactive brew (Ayahuasca) made from a mixture of botanicals. Five plant species used in Ayahuasca preparations were subjected to DART-HRMS analysis. The chemical fingerprint of each was reproducible but unique, thus enabling discrimination between them. The presence of important biomarkers, including $N, N$ dimethyltryptamine, harmaline and harmine, was confirmed using in-source collision-induced dissociation (CID). Six Ayahuasca brews made from combinations of various plant species were shown to possess a high level of similarity, despite having been made from different constituents. Nevertheless, the application of principal component analysis (PCA) was useful in distinguishing each of the brews based on the botanical species used in the preparations. From a training set based on 900 individual analysis, three principal components covered $86.38 \%$ of the variance, and the leave-one-out cross validation was $98.88 \%$. This is the first report of ambient ionization MS being successfully used for the determination of individual components of plant mixtures. 


\section{KEYWORDS}

DART-HRMS, Ayahusaca, ambient ionization, drug analysis, dimethyltryptamine (DMT) plantbased drugs of abuse 


\section{INTRODUCTION}

Despite continuing advances in separations science, the ability to accurately determine the originating constituents of compounded mixtures of complex plant matrices remains a challenge in analytical chemistry. One area that would benefit significantly from progress in this regard is forensics, where knowledge of the component species of psychoactive brews made from multiple plants can be of critical importance to law enforcement, toxicologists and medical practitioners treating patients who have overdosed on psychoactive substances. The United Nations Office on Drugs and Crime (UNODC) has reported an alarming and exponential rise in the use of unscheduled psychoactive plant substances. This increase has been attributed to multiple factors including the desire by users to: (1) experience mind-altering effects without fear of prosecution from violation of current drug laws; (2) intensify the effects of more mainstream prescription and/or illicit drugs; and (3) have "spiritual" or "supernatural" experiences. Many users also have the perception that plant-based psychoactive substances are safer than scheduled substances because they are "natural." These widely held perspectives belie the dangers associated with consumption of these products. The use of these botanical psychotropic products have been implicated in multiple poisonings and fatalities.[1-8]

Although inroads are being made into the identification of abused substances derived from single plant species, $[9,10]$ a major challenge that confronts efforts to curtail the use of plant psychoactives is the absence of suitable analytical methods to accurately identify compounded plant-based products. Prescription and illicit drugs, as well as synthetic cathinones and cannabinoid products, are generally comprised of pure or semi-purified components that 
can be identified by conventional analytical techniques. However, the complex matrices associated with whole plant materials or concoctions made from them, make definitive identification of the constituents very difficult. Since scheduling of mind-altering products requires the ability to identify the outlawed substance, and since methods for identification are by and large non-existent for plant-based psychotropics (except in the cases of cannabis, peyote, opium and a few others), law enforcement has been rendered powerless to intervene. Furthermore, because it is often impossible to determine the identity of ingested mind-altering plants in cases of drug overdoses, appropriate life-saving protocols cannot be administered.

One well-known hallucinogenic beverage of South American origin is Ayahuasca, also commonly known as yage, hoasca or caapi.[11-16] Its consumption is an important part of some South American religious ceremonies and it is purported to cause users to experience visions and clairvoyance. Although its use among some groups in ceremonial religious contexts is legal, the appeal of Ayahuasca as a recreational drug is increasing in the United States and Europe. However, despite its legal status, the indiscriminate consumption of Ayahuasca and the plants used to make the brew has been implicated in poisonings.[2, 6, 17-19] It has also been found in clandestine laboratories where more mainstream drugs of abuse are manufactured.[20-22] When observed in the context of crime scene investigations, psychoactive plant substances or brews are not easily identifiable, particularly in cases where varying combinations of plant materials are used to make the concoctions, as is the case with Ayahuasca. For this reason, it is important to be able to determine the plant species from which the brews are made so that the identity of the mind-altering compounds can be known and appropriate treatment protocols for overdoses can be applied. 
The hallucinogenic effects of Ayahuasca are derived from $\mathrm{N}, \mathrm{N}$-dimethyltryptamine (DMT) which is extracted from botanical material and concentrated during the brewing process. DMT-containing plants commonly used in preparation of the brew include Psychotria viridis (Chacruna), Mimosa hostilis (Jurema) and Diplopterys cabrerana (Chaliponga).[12, 23-25] The effects of oral administration of DMT are minimal because of the action of monoamine oxidase (MAO) enzymes which de-aminate the compound to form non-psychoactive derivatives. For this reason, the psychoactive effects of orally ingested DMT require concurrent consumption of an MAO inhibitor (MAOI). Plant-derived $\beta$-carboline alkaloids such as harmine, harmaline and tetrahydroharmine (Figure 1)[16, 18, 24, 26-28] serve this purpose. Thus, Ayahuasca brews contain plant combinations that contribute both DMT and $\beta$-carbolines.[23, 25, 28-30] Banisteriopsis caapi (yage) and Peganum harmala (Syrian rue) are the two most common $\beta$ carboline-containing plants used in these preparations. With inhibition of the MAOs by the harmala alkaloids, the effects of DMT, which include intense visual hallucinations, auditory distortions and an altered sense of being, occur. These experiences are attributed to DMT-promoted $5-\mathrm{HT}_{2 \mathrm{~A}}$, 5- $\mathrm{HT}_{1 \mathrm{~A}}$, and $5-\mathrm{HT}_{2 \mathrm{c}}$ serotonergic receptor agonism.[28, 31] Peak effects

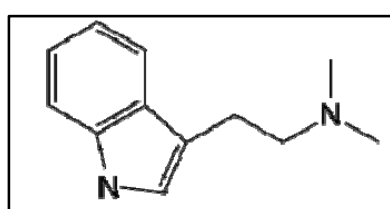
$N, N$-Dimethyltryptamine $\mathrm{C}_{12} \mathrm{H}_{16} \mathrm{~N}_{2}$

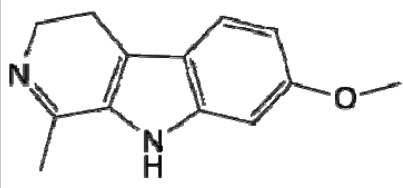

Harmaline $\mathrm{C}_{13} \mathrm{H}_{14} \mathrm{~N}_{2} \mathrm{O}$<smiles>OC1CCN2Cc3ccccc3N=C12</smiles>
Vasicine $\mathrm{C}_{11} \mathrm{H}_{12} \mathrm{~N}_{2} \mathrm{O}$

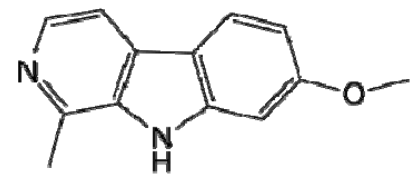

Harmine $\mathrm{C}_{13} \mathrm{H}_{12} \mathrm{~N}_{2} \mathrm{O}$

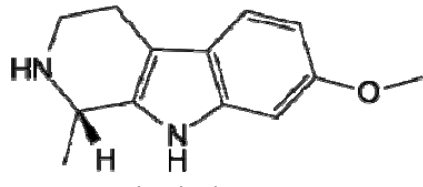

Tetrahydroharmine $\mathrm{C}_{13} \mathrm{H}_{16} \mathrm{~N}_{2} \mathrm{O}$<smiles>CC1CCN2Cc3ccccc3N=C12</smiles>

Deoxypeganine $\mathrm{C}_{11} \mathrm{H}_{12} \mathrm{~N}_{2}$

Figure 1: Psychoactive alkaloids and $\beta$-carbolines reported to be found in Ayahuasca brews.

occur rapidly and diminish within 30 
minutes, without the extended period of mind-altering effects that occur with other hallucinogens.[32]

While DMT is a Schedule I substance in the United States and under international law, Ayahuasca brews and the plant materials from which the psychoactive compounds are derived remain in a legal grey area. Plants containing scheduled compounds or infusions made from them are not included in the 1971 Convention of Psychotropic Substances, and in the United States, only marijuana, peyote and psilocybin mushrooms are specifically scheduled plant materials. [33, 34] Because the presence of identification protocols is a necessary prerequisite to the legislation of mind-altering materials, the development of methods to accurately confirm the identity of plant-based drugs of abuse is of high concern, as highlighted in the 2009 National Academy of Science report on the status of forensic sciences in the United States.[35] The characterization of Ayahuasca or its plant constituents in a forensic context is mainly limited to the detection of DMT in the brew or botanical material. Conventional time intensive protocols utilizing chromatographic or hyphenated methods such as HPLC-fluorescence,[36] gas chromatography (GC)- or liquid chromatography-mass spectrometry (LC-MS) have been used to isolate and identify DMT and harmala alkaloids in Ayahuasca.[30, 37-41] Typically, plant samples or Ayahuasca brews are subjected to liquid-liquid or Soxhlet extraction, which consume large amounts of solvent prior to analysis by HPLC or LC.[41] Sample preparation for GC methods can be even more cumbersome because aqueous samples cannot be analyzed directly. Furthermore, there are no standard operating protocols for the analysis of the plant materials used for Ayahuasca, including $P$. viridis, $M$. hostilis and D. cabrerana, B. caapi and $P$. harmala. Intensive method development is also needed to optimize chromatographic 
separation of the components in the brew, which adds to the overall analysis time. For unscheduled substances such as Ayahuasca brews and the psychoactive plant materials used for the concoction, it is often not worth the investment of time or resources to conduct the analysis, especially in light of the casework backlogs faced by forensic laboratories.[42]

The advent of ambient ionization mass spectrometry, and direct analysis in real timehigh resolution mass spectrometry (DART-HRMS) in particular, has allowed analysts to circumvent some of the aforementioned difficulties in identifying forensic material including botanical or plant-based substances. Solids, liquids and gases can be easily analyzed using DART-HRMS without the need for lengthy sample preparation steps such as extractions or derivatization. $[43,44]$ It has been demonstrated previously that forensically relevant plant material, including seeds, leaves, and wood, can be analyzed for detection of biomarkers, and that the chemical fingerprint produced can provide species-level discrimination and identification of mind-altering plant substances using statistical analysis tools.[9, 10, 45] However, this method has not been successfully applied to compounded mixtures comprised of complex matrices. We surmised that DART-HRMS might be an ideal method for the characterization and identification of Ayahuasca brew components. Unlike the case with GCMS, it can be used for direct analysis of aqueous samples and no extraction steps, filtrations, $\mathrm{pH}$ adjustments, derivatizations or other sample processing steps are required. Furthermore, the individual botanical species of which the brew is comprised can be sampled in the same manner, which permits utilization of the chemical fingerprint of each for identification of the plant species within the brew. The coupling of the DART-HRMS data with statistical analysis processing might then furnish accurate mixture component information, a determination that is 
impractical, if not impossible, using chromatographic or hyphenated methods, due to the time investment required to obtain the large datasets needed for validation.

To test the proof of principle that chemometric processing of DART-HRMS derived chemical profiles of mixtures of plant products might enable plant constituent determination, we applied the method to Ayahuasca concoctions. In-source collision-induced dissociation was used to confirm the presence of DMT in $P$. viridis, M. hostilis and D. cabrerana, and the two harmala alkaloids harmine and harmaline were confirmed in B. caapi and P. harmala. Principal component analysis (PCA) was successfully applied to the DART-HRMS data of Ayahuasca brews made following 6 different recipes, and the plant species of which each brew was comprised were rapidly and accurately determined with $>98 \%$ confidence.

\section{EXPERIMENTAL}

\section{Botanical materials}

Banisteriopsis caapi shredded vine and Peganum harmala seeds were purchased from World Seed Supply (Mastic Beach, NY, USA). Mimosa hostilis root bark and Psychotria viridis dried leaves were purchased from Mr. Botanicals (mrbotanicals.com, Netherlands). Diplopterys cabrerana leaves were purchased from Herbal Flame (Hollywood, FL, USA). 


\section{Chemical standards}

$N, N$-Dimethyltryptamine was purchased from Cerilliant Corporation (Round Rock, TX, USA). Harmaline, harmine, and vasicine standards were purchased from Sigma Aldrich (St. Louis, MO, USA).

\section{Ayahuasca brew preparation}

Ayahuasca brews were made according to published protocols[24] that were scaled down to make smaller batches (using approximately $30 \mathrm{~g}$ of plant material). The first Ayahuasca brew was made using $15 \mathrm{~g}$ of $B$. caapi vine and $15 \mathrm{~g}$ of $P$. viridis leaves that were pulverized using a Hamilton Beach coffee grinder (Glen Allen, VA, USA). The mixture was refluxed in 250 $\mathrm{mL}$ of water with $5 \mathrm{~mL}$ of lemon juice (Sicilia brand, Clifton, NJ, USA) for three hours. The liquid was passed through a coffee filter and the filtrate was analyzed by DART-HRMS. The remaining residue was refluxed in another $250 \mathrm{~mL}$ aliquot of water with $5 \mathrm{~mL}$ of lemon juice for three hours. The suspension was again filtered and the filtrate analyzed by DART-HRMS. The two filtrate fractions were then pooled and again analyzed by DART-HRMS. All other Ayahuasca brews were made following the protocol described above, but using the following plant material combinations: Ayahuasca brew 2 was prepared with $24 \mathrm{~g}$ of $M$. hostilis root bark and 6 g of $P$. harmala seeds that were ground; Ayahuasca brew 3 was made using $24 \mathrm{~g}$ of $P$. viridis leaves and $4 \mathrm{~g}$ of $P$. harmala seeds; Ayahuasca brew 4 consisted of $25 \mathrm{~g}$ of B. caapi vine and 7.5 $\mathrm{g}$ of $M$. hostilis root bark; the fifth and sixth Ayahuasca brews were made using $7 \mathrm{~g}$ of $D$. 
cabrerana leaves and $20 \mathrm{~g}$ of B. caapi vine, and $24 \mathrm{~g}$ of $D$. cabrerana leaves and $4 \mathrm{~g}$ of $P$. harmala seeds, respectively. For ease of reference, the brew compositions are listed in Table 1).

\begin{tabular}{|l|c|c|}
\hline \multicolumn{3}{|c|}{ Table 1. Botanical species composition of six Ayahuasca brews. } \\
\hline & $\begin{array}{c}\text { DMT-Contributing } \\
\text { Species }\end{array}$ & $\begin{array}{c}\text { Harmala Alkaloid-Contributing } \\
\text { Species }\end{array}$ \\
\hline Brew 1 & P. viridis & B. caapi \\
\hline Brew 2 & M. hostilis & P. harmala \\
\hline Brew 3 & P. viridis & P. harmala \\
\hline Brew 4 & M. hostilis & B. caapi \\
\hline Brew 5 & D. cabrerana & B. caapi \\
\hline Brew 6 & D. cabrerana & P. harmala \\
\hline
\end{tabular}

Mass spectral data collection and analysis

Mass spectra were acquired using a DART-SVP ion source (IonSense, Saugus, MA, USA) coupled to a JEOL AccuTOF high resolution time-of-flight mass spectrometer (JEOL USA, Peabody, MA, USA) in positive-ion mode. The parameters of the DART ion source were: grid voltage, $250 \mathrm{~V}$; and gas heater temperature, $350{ }^{\circ} \mathrm{C}$. The mass spectrometer settings were: ring lens voltage, $5 \mathrm{~V}$; orifice 1 voltage, $20 \mathrm{~V}$; orifice 2 voltage, $5 \mathrm{~V}$; and RF ion guide ("peaks") voltage, $600 \mathrm{~V}$. Mass spectra were acquired over the $m / z$ range $60-800$ at a spectral acquisition rate of 1 spectrum per sec. The helium flow rate for the DART ion source was $2.0 \mathrm{~L} \mathrm{~s}^{-1}$. The resolving power of the mass spectrometer was $6000 \mathrm{FWHM}$.

In-source collision-induced dissociation (CID) can be used for structural confirmation of compounds in the plant materials through comparison of in-source CID spectra of authentic standards to those of the plant material obtained under identical conditions. For structural confirmation of DMT, harmaline and harmine, in-source CID was performed on plant material and standards using "function switching," whereby the orifice 1 voltage of the mass 
spectrometer was varied from $20 \mathrm{~V}$ to 30,60 , and $90 \mathrm{~V}$ to induce fragmentation of the compounds within a single analysis. The RF ion guide ("peaks") voltage was set to $400 \mathrm{~V}$ for CID analysis and the mass range was set to $\mathrm{m} / \mathrm{z} 40-800$. All other ion source and mass spectrometer parameters were as described above.

The $P$. viridis and $D$. cabrerana leaves were tested directly by grasping the material with tweezers and suspending it between the ion source and mass spectrometer inlet. The $M$. hostilis root bark and $B$. caapi vine were sampled in the same manner. The $P$. harmala seeds were sliced in half transversely and then held with tweezers between the ion source and inlet of the mass spectrometer. Five analyses were averaged in each spectrum and five replicates were obtained for each species. DMT, harmine and harmaline were sampled by dipping the closed end of a melting point capillary tube into the standard and presenting the coated surface of the tube to the space between the DART ion source and mass spectrometer inlet.

The Ayahuasca brews were analyzed by inserting 10 Diplt $^{\circledR}$ tip capillary tubes (IonSense, Saugus, MA, USA) into the liquid and then mounting the tips into the 12-unit sample holder on a linear rail system (IonSense, Saugus, MA, USA) that moved laterally from left to right between the ion source and the mass spectrometer inlet at a rate of $1.0 \mathrm{~mm} / \mathrm{s}$. This sampling process provided reproducible, high-throughput analysis of the Ayahuasca brews. Five analyses were averaged for each spectrum and thirty spectra were collected for each of the Ayahuasca brews. In each case, ten spectra were collected from the first fraction, ten from the second fraction and ten from the combined fraction, resulting in 900 individual analyses. 
Mass spectral data processing

Calibration of all spectra was performed using polyethylene glycol (PEG) 600. Spectral averaging, calibration, background subtraction and peak centroiding were performed using TSSPro3 (Shrader Analytical Labs, Detroit, MI, USA) data processing software. Mass Mountaineer software (RBC Software, mass-spec-software.com) was used for mass spectral analysis, elemental composition determination, isotopic analysis and principal component analysis.

\section{RESULTS}

\section{DART-HRMS Analysis of Ayahuasca Botanical Species}

The botanical species used in the making of Ayahuasca brews contain compounds that are known to be either psychoactive (e.g. DMT) or serve as MAOIs (e.g. harmaline and harmine). To determine the presence of these compounds in the plant materials, five different botanical species were purchased from various internet vendors and the plant materials were subjected to DART-HRMS analysis. The results of the analyses are shown in Figure 2, with the corresponding mass measurement data presented in Table 2. In each case, an average of five spectra are shown and each peak in the spectrum represents a unique protonated compound.

Panels a, c and e are representative spectra of $P$. viridis, $M$. hostilis and $D$. cabrerana, respectively, plants that are reported to contain the psychoactive alkaloid DMT. In each case, a peak at nominal mass $\mathrm{m} / \mathrm{z} 189$ was detected, consistent with the presence of protonated DMT $\left(\mathrm{C}_{12} \mathrm{H}_{16} \mathrm{~N}_{2}+\mathrm{H}^{+}\right)$. N-Methyltryptamine $\left(\mathrm{C}_{11} \mathrm{H}_{14} \mathrm{~N}_{2}+\mathrm{H}^{+}\right)$at nominal $\mathrm{m} / z 175$ was also detected in 
the $P$. viridis, $M$. hostilis and $D$. cabrerana botanical samples. In each case, the peak at nominal $\mathrm{m} / \mathrm{z} 189$ was the most abundant in the spectrum at $100 \%$ relative intensity, and the relative intensity of $\mathrm{N}$-methyltryptamine varied between 0.4 and $9.8 \%$. In the analysis of the harmala alkaloid-containing plants $B$. caapi and $P$. harmala, masses consistent with previously reported compounds were detected.[25, 26, 29, 30, 40,46] In the B. caapi shredded vine, peaks at nominal $m / z$ 199, 213, 215 and 217 corresponding to harmol $\left(\mathrm{C}_{12} \mathrm{H}_{10} \mathrm{~N}_{2} \mathrm{O}+\mathrm{H}^{+}\right)$, harmine

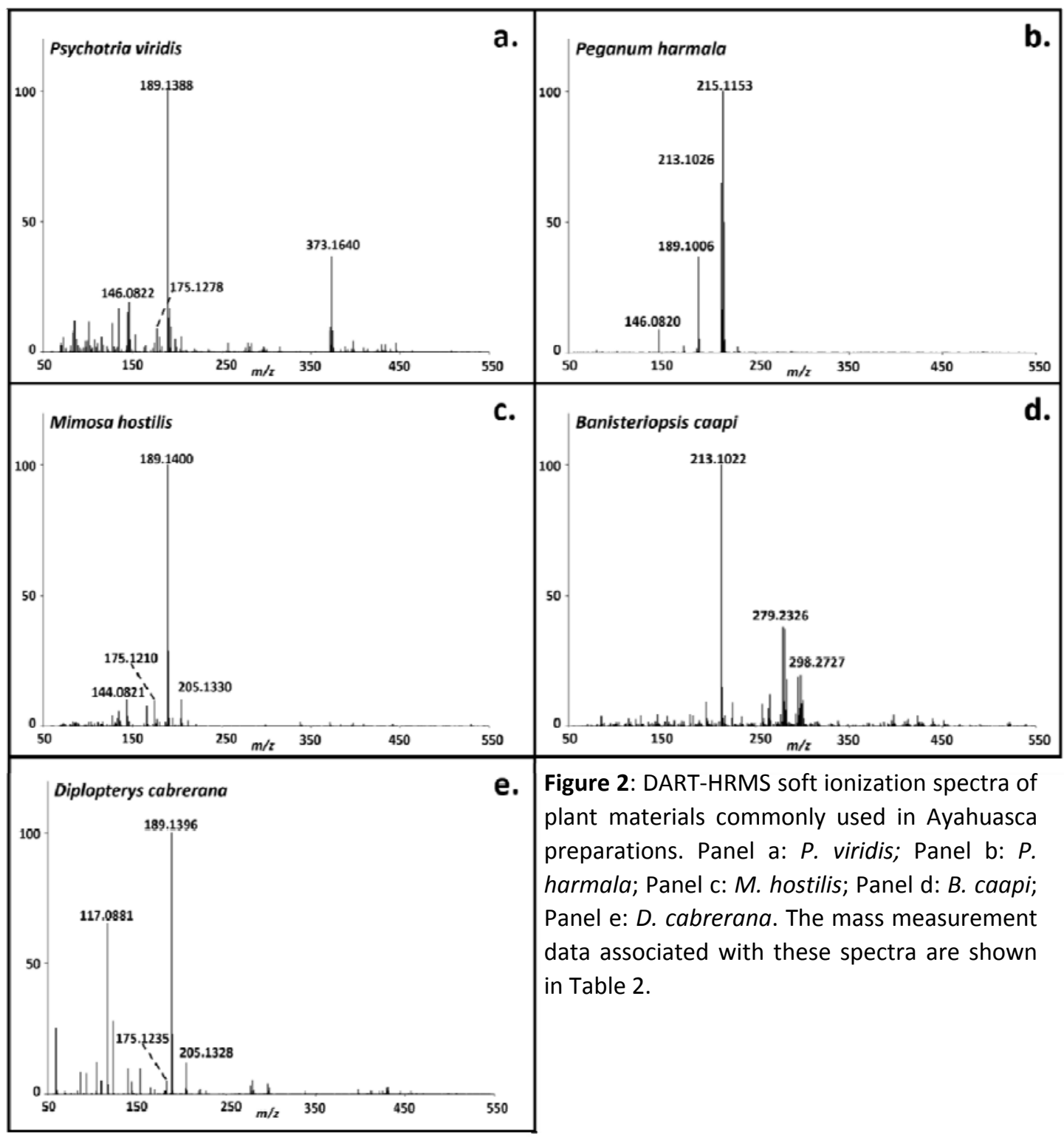


$\left(\mathrm{C}_{13} \mathrm{H}_{12} \mathrm{~N}_{2} \mathrm{O}+\mathrm{H}^{+}\right)$, harmaline $\left(\mathrm{C}_{13} \mathrm{H}_{14} \mathrm{~N}_{2} \mathrm{O}+\mathrm{H}^{+}\right)$and tetrahydroharmine $\left(\mathrm{C}_{13} \mathrm{H}_{16} \mathrm{~N}_{2} \mathrm{O}+\mathrm{H}^{+}\right)$, respectively were identified, with $\mathrm{m} / \mathrm{z} 213$ presenting as the base peak. Masses consistent with harmine $\left(\mathrm{C}_{13} \mathrm{H}_{12} \mathrm{~N}_{2} \mathrm{O}+\mathrm{H}^{+}, \mathrm{m} / z\right.$ 213.1026), and harmaline $\left(\mathrm{C}_{13} \mathrm{H}_{14} \mathrm{~N}_{2} \mathrm{O}+\mathrm{H}^{+}, \mathrm{m} / z\right.$ 215.1153) were also present in the $P$. harmala seeds, in addition to peaks at $m / z 173.1069$ and 189.1006 , corresponding to deoxypeganine $\left(\mathrm{C}_{11} \mathrm{H}_{12} \mathrm{~N}_{2}+\mathrm{H}^{+}\right)$and vasicine $\left(\mathrm{C}_{11} \mathrm{H}_{12} \mathrm{~N}_{2} \mathrm{O}+\mathrm{H}^{+}\right)$respectively. In the case of $P$. harmala, the peak at $m / z 213$ corresponding to harmaline was the base peak. The peak at $m / z 215$, consistent with the presence of harmine, had a relative intensity of $64.9 \%$.

\begin{tabular}{|c|c|c|c|c|c|c|}
\hline Product & Compound & Formula & Measured & Calculated & Diff. $^{+}$ & Rel. Int. ${ }^{\ddagger}$ \\
\hline \multirow{2}{*}{$\begin{array}{c}\text { Psychotria } \\
\text { viridis }\end{array}$} & $\mathrm{N}$-Methyltryptamine ${ }^{\mathrm{a}}$ & $\mathrm{C}_{11} \mathrm{H}_{14} \mathrm{~N}_{2}+\mathrm{H}^{+}$ & 175.1278 & 175.1235 & -4.3 & 1.6 \\
\hline & Dimethyltryptamine $^{b}$ & $\mathrm{C}_{12} \mathrm{H}_{16} \mathrm{~N}_{2}+\mathrm{H}^{+}$ & 189.1388 & 189.1392 & 0.4 & 100.0 \\
\hline \multirow{2}{*}{ Mimosa hostilis } & $N$-Methyltryptamine ${ }^{a}$ & $\mathrm{C}_{11} \mathrm{H}_{14} \mathrm{~N}_{2}+\mathrm{H}^{+}$ & 175.1210 & 175.1235 & 2.5 & 9.8 \\
\hline & Dimethyltryptamine $^{b}$ & $\mathrm{C}_{12} \mathrm{H}_{16} \mathrm{~N}_{2}+\mathrm{H}^{+}$ & 189.1400 & 189.1392 & -0.8 & 100.0 \\
\hline \multirow{4}{*}{$\begin{array}{l}\text { Banisteriopsis } \\
\text { caapi }\end{array}$} & Harmol $^{\mathrm{a}}$ & $\mathrm{C}_{12} \mathrm{H}_{10} \mathrm{~N}_{2} \mathrm{O}+\mathrm{H}^{+}$ & 199.0875 & 199.0871 & -0.4 & 1.6 \\
\hline & Harmine $^{b}$ & $\mathrm{C}_{13} \mathrm{H}_{12} \mathrm{~N}_{2} \mathrm{O}+\mathrm{H}^{+}$ & 213.1022 & 213.1028 & 0.6 & 100.0 \\
\hline & Harmaline $^{b}$ & $\mathrm{C}_{13} \mathrm{H}_{14} \mathrm{~N}_{2} \mathrm{O}+\mathrm{H}^{+}$ & 215.1153 & 215.1184 & 3.1 & 3.0 \\
\hline & Tetrahydroharmine $^{a}$ & $\mathrm{C}_{13} \mathrm{H}_{16} \mathrm{~N}_{2} \mathrm{O}+\mathrm{H}^{+}$ & 217.1353 & 217.1341 & -1.2 & 4.1 \\
\hline \multirow{4}{*}{$\begin{array}{c}\text { Peganum } \\
\text { harmala }\end{array}$} & Deoxypeganine $^{a}$ & $\mathrm{C}_{11} \mathrm{H}_{12} \mathrm{~N}_{2}+\mathrm{H}^{+}$ & 173.1069 & 173.1079 & 1.0 & 2.5 \\
\hline & Vasicine $^{\mathrm{b}}$ & $\mathrm{C}_{11} \mathrm{H}_{12} \mathrm{~N}_{2} \mathrm{O}+\mathrm{H}^{+}$ & 189.1006 & 189.1028 & 2.2 & 36.6 \\
\hline & Harmine $^{b}$ & $\mathrm{C}_{13} \mathrm{H}_{12} \mathrm{~N}_{2} \mathrm{O}+\mathrm{H}^{+}$ & 213.1026 & 213.1028 & 0.2 & 64.9 \\
\hline & Harmaline $^{\mathrm{b}}$ & $\mathrm{C}_{13} \mathrm{H}_{14} \mathrm{~N}_{2} \mathrm{O}+\mathrm{H}^{+}$ & 215.1153 & 215.1184 & 3.1 & 100.0 \\
\hline \multirow{2}{*}{$\begin{array}{l}\text { Diplopterys } \\
\text { cabrerana }\end{array}$} & $\mathrm{N}$-Methyltryptamine ${ }^{\mathrm{a}}$ & $\mathrm{C}_{11} \mathrm{H}_{14} \mathrm{~N}_{2}+\mathrm{H}^{+}$ & 175.1235 & 175.1235 & -1.5 & 0.4 \\
\hline & Dimethyltryptamine & $\mathrm{C}_{12} \mathrm{H}_{16} \mathrm{~N}_{2}+\mathrm{H}^{+}$ & 189.1392 & 189.1392 & -0.4 & 100.0 \\
\hline \multicolumn{7}{|c|}{$\begin{array}{l}{ }^{\mathrm{a}} \text { The corresponding mass was consistent with the formula of the indicated compound which has previously been } \\
\text { isolated from the species listed. } \\
\text { b The presence of this compound was confirmed through comparison of in-source collision-induced dissociation } \\
\text { (CID) spectrum of the plant material with the in-source CID spectrum of an authentic standard. } \\
\text { 'Differences are reported in millimass units (mmu). Measured masses fell within } 5 \mathrm{mmu} \text { of the calculated } \\
\text { masses. } \\
{ }^{\ddagger} \text { Relative intensities are reported in percent. }\end{array}$} \\
\hline
\end{tabular}




\section{In-source Collision-Induced Dissociation Experiments}

DART-HRMS analysis under soft-ionization conditions provides chemical formula information that allows tentative assignment of compounds based on those previously reported to be present in the analyzed species. This is done through comparison of in-source CID spectra of authentic standards to those of plant material obtained under identical conditions. $[9,10]$ The AccuTOF "function switching" feature enables the simultaneous collection of mass spectra under soft ionization conditions (i.e. low orifice 1 voltages), and insource CID conditions (using higher orifice 1 voltages) which promote fragmentations characteristic of the molecule being analyzed. To confirm the presence of DMT in $P$. viridis, $M$. hostilis and D. cabrerana, in-source CID analysis using function switching was performed. For DMT, an orifice 1 voltage of $60 \mathrm{~V}$ yielded the best results in that the protonated parent molecule was retained while the fragment ions were still detected. Representative spectra are illustrated in Figure 3 as head-to-tail plots. In each of the Panels a through c, the in-source CID spectrum of the plant material is on top and that of DMT appears on the bottom. The mass measurement data associated with the spectra are presented in Supplementary Material Tables S-1 - S-3. The parent peak for DMT at nominal $\mathrm{m} / \mathrm{z} 189$ was detected in the plant material as well as in the standard in each case. Fragment ions at nominal $\mathrm{m} / \mathrm{z} 160,144$, and 58 corresponding to $\mathrm{C}_{10} \mathrm{H}_{10} \mathrm{NO}, \mathrm{C}_{10} \mathrm{H}_{10} \mathrm{~N}$, and $\mathrm{C}_{3} \mathrm{H}_{8} \mathrm{~N}$, respectively, were detected in $P$. viridis, $M$. hostilis, D. cabrerana and the standard, confirming the presence of DMT in each of the plant materials. 


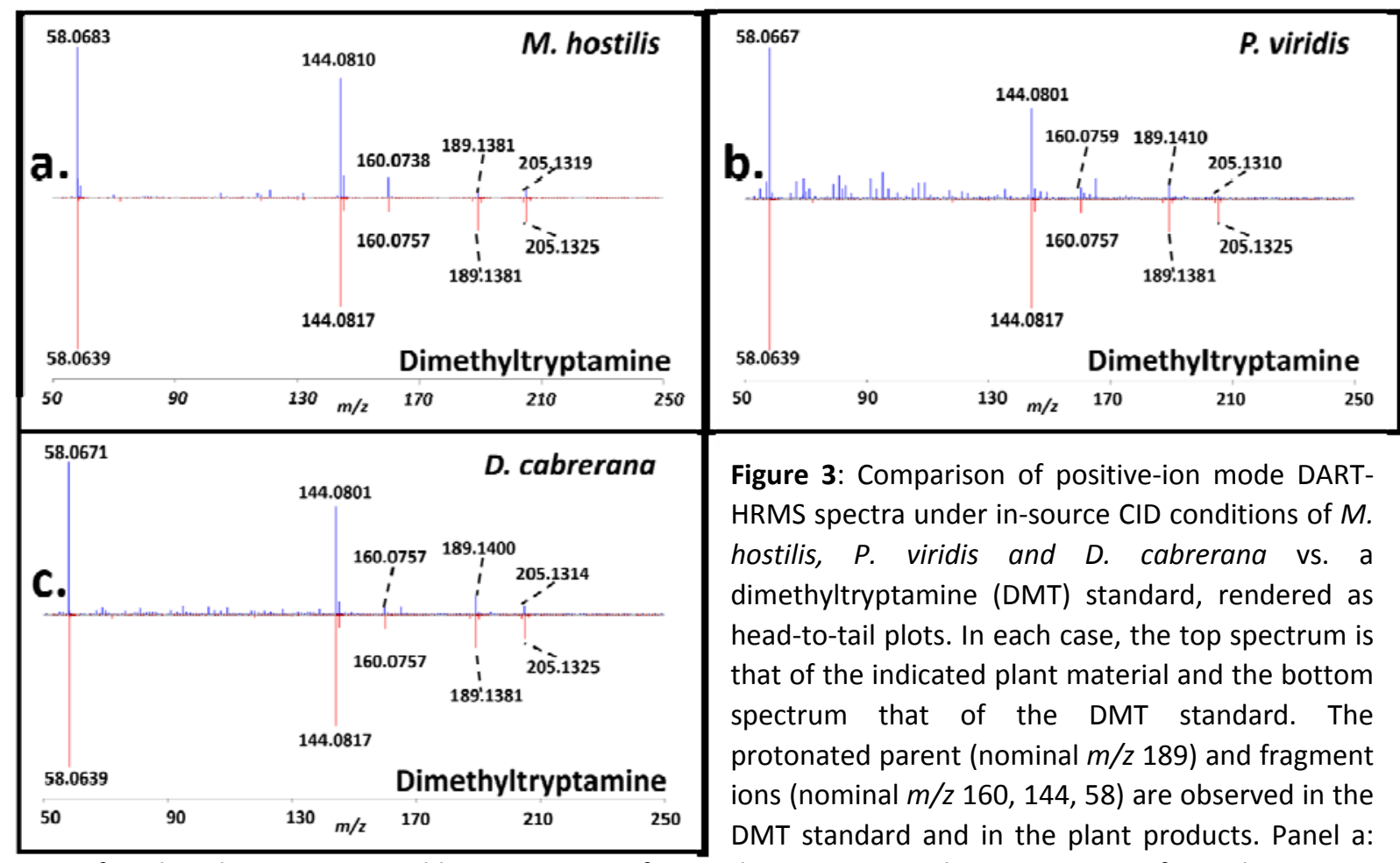

ison of M. hostilis to DMT; Panel b: comparison of $P$. viridis to DMT; Panel c: comparison of $D$. cabrerana to DMT. The mass measurement data associated with these spectra are shown in Tables S-1 - S-3.

In-source CID analysis was also performed on B. caapi and P. harmala to confirm the presence of harmine and harmaline, the bioactive $\beta$-carbolines reported[16, 18, 24, 26-28] in these plants. Figure 4 shows the in-source CID spectra at $90 \mathrm{~V}$ of $B$. caapi and $P$. harmala rendered as head-to-tail plots, with mass measurement data presented in Supplementary Material Tables S-4 - S-7. In Panels $a$ and b, the in-source CID spectrum of the plant material is on top and that of harmaline appears on the bottom, while in Panels $c$ and $d$, harmine appears on the bottom of the head-to-tail plots. The in-source CID spectrum of the harmaline standard shown in Panels $a$ and $b$ exhibited a parent peak at nominal $m / z 215$ with fragment ions at nominal $\mathrm{m} / \mathrm{z} 200,174,172,159$ and 68 . The parent peak and corresponding fragment ions were also found in the B. caapi and P. harmala in-source CID spectra. However, the abundances in 
the $B$. caapi spectrum were much lower, due to the overall lower intensity of the harmaline peak in the soft ionization spectrum of the plant material (Figure 2d). Harmine was confirmed to be present in both B. caapi and P. harmala based on the comparison of the plant material 90 $V$ spectra to that of the harmine standard. Panels $c$ and $d$ exhibited a parent peak at nominal $m / z 213$ for the harmine standard, as well as fragment ions at nominal $m / z 199,198,171$ and 170. The $90 \mathrm{~V}$ spectra of $B$. caapi and $P$. harmala both exhibited a parent peak at nominal $\mathrm{m} / \mathrm{z}$ 213 and fragments at nominal $m / z$ 199, 198, 171 and 170, confirming the presence of harmine

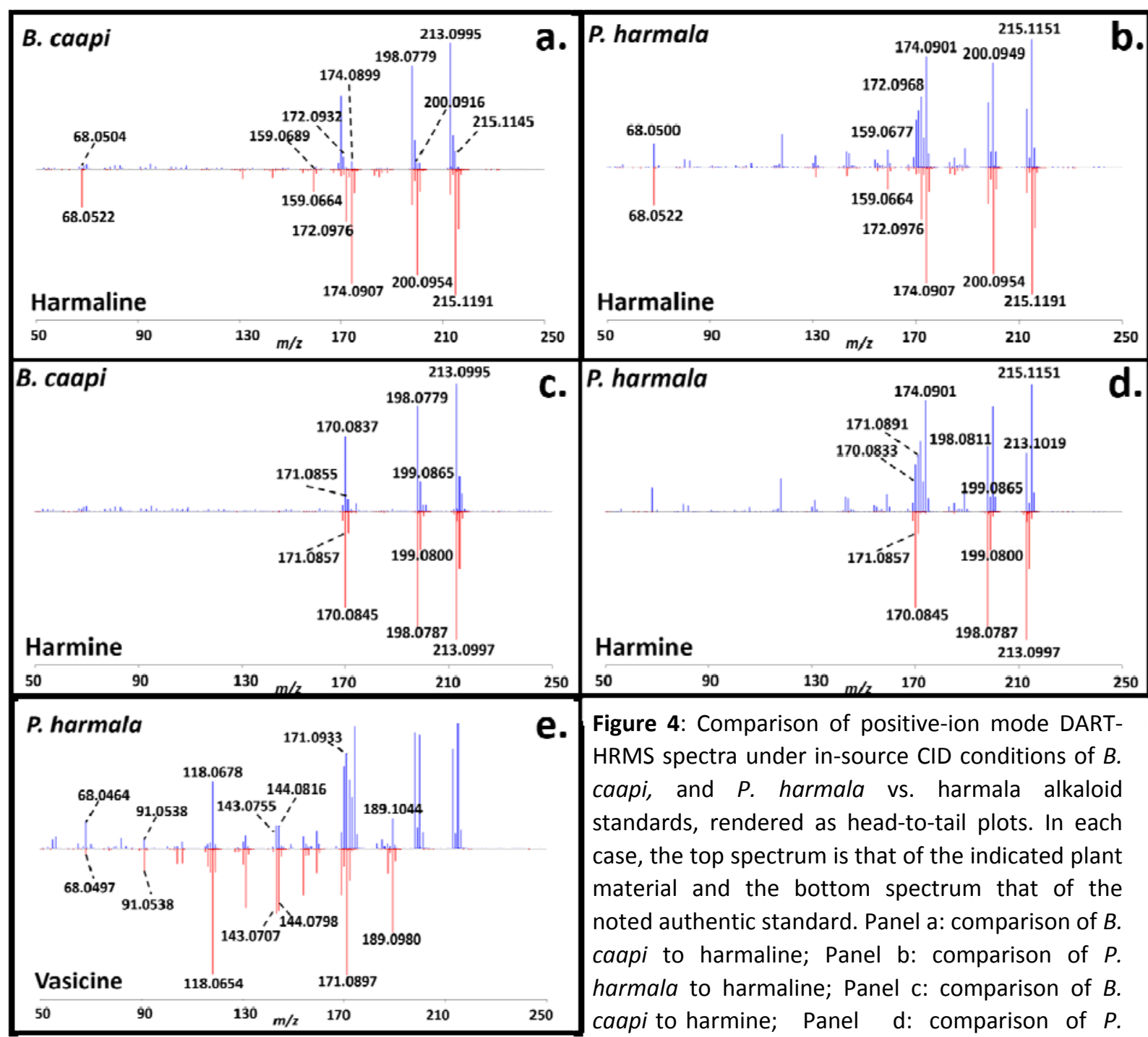

harmine; Panel e: comparison of $P$. harmala to vasicine. The mass measurement data associated with these spectra are shown in Tables S-4 - S-8. 
in the botanical material. In-source CID also confirmed the presence of vasicine in the $P$. harmala seeds (Supplementary Material Figure S-2e). The $90 \mathrm{~V}$ spectra of the seed and vasicine standard have a parent peak at nominal $m / z 189$, with fragments at nominal $m / z 171,144,143$, 118, 91 and 68 (Supplementary Material Table S-8).

\section{Classification of Ayahuasca Brew DART-HRMS Data by Principal Component Analysis}

Upon determination of the unique chemical fingerprints associated with each of the botanical materials typically used in Ayahuasca, brews were concocted to ascertain whether the identity of the plants used in the extraction could be elucidated. Six brews were made following readily available recipes: ${ }^{24}$ brew $1: B$. caapi and $P$. viridis; brew 2: $M$. hostilis and $P$. harmala; brew 3: P. viridis and P. harmala; brew 4: $M$. hostilis and B. caapi; brew 5: D. cabrerana and B. caapi; and brew 6: D. cabrerana and P. harmala. The DART-HRMS analysis of the six brews conducted under soft ionization conditions (i.e. orifice 1 voltage of $20 \mathrm{~V}$ ) are illustrated in Figure 5, with corresponding mass measurement data listed in Supplementary Information Table S-9. Each spectrum is an average of five spectra, with each peak representing a protonated molecule. A total of 30 averaged spectra were obtained for each brew, resulting in 900 individual analyses. The inset in each Panel is an image of the indicated brew, and illustrates the subtle differences in the appearances of the brews made by the different methods. DMT (nominal $\mathrm{m} / \mathrm{z} 189$ ), $N$-methyltryptamine (nominal $\mathrm{m} / \mathrm{z}$ 175), harmine (nominal $\mathrm{m} / \mathrm{z} 213$ ) and harmaline (nominal $\mathrm{m} / \mathrm{z} 215$ ) were detected in all of the brews, with intensities ranging from $77.1 \%-100 \%, 1.1-5.1 \%, 36.8-77.1 \%$ and $2.1-73.7 \%$, respectively. Harmane 
(nominal $\mathrm{m} / \mathrm{z}$ 183) was present in brews made with $B$. caapi (Panels a, d, and e) and deoxypeganine (nominal $\mathrm{m} / z$ 173) was detected in the brews containing $P$. harmala seeds (b, c and f).

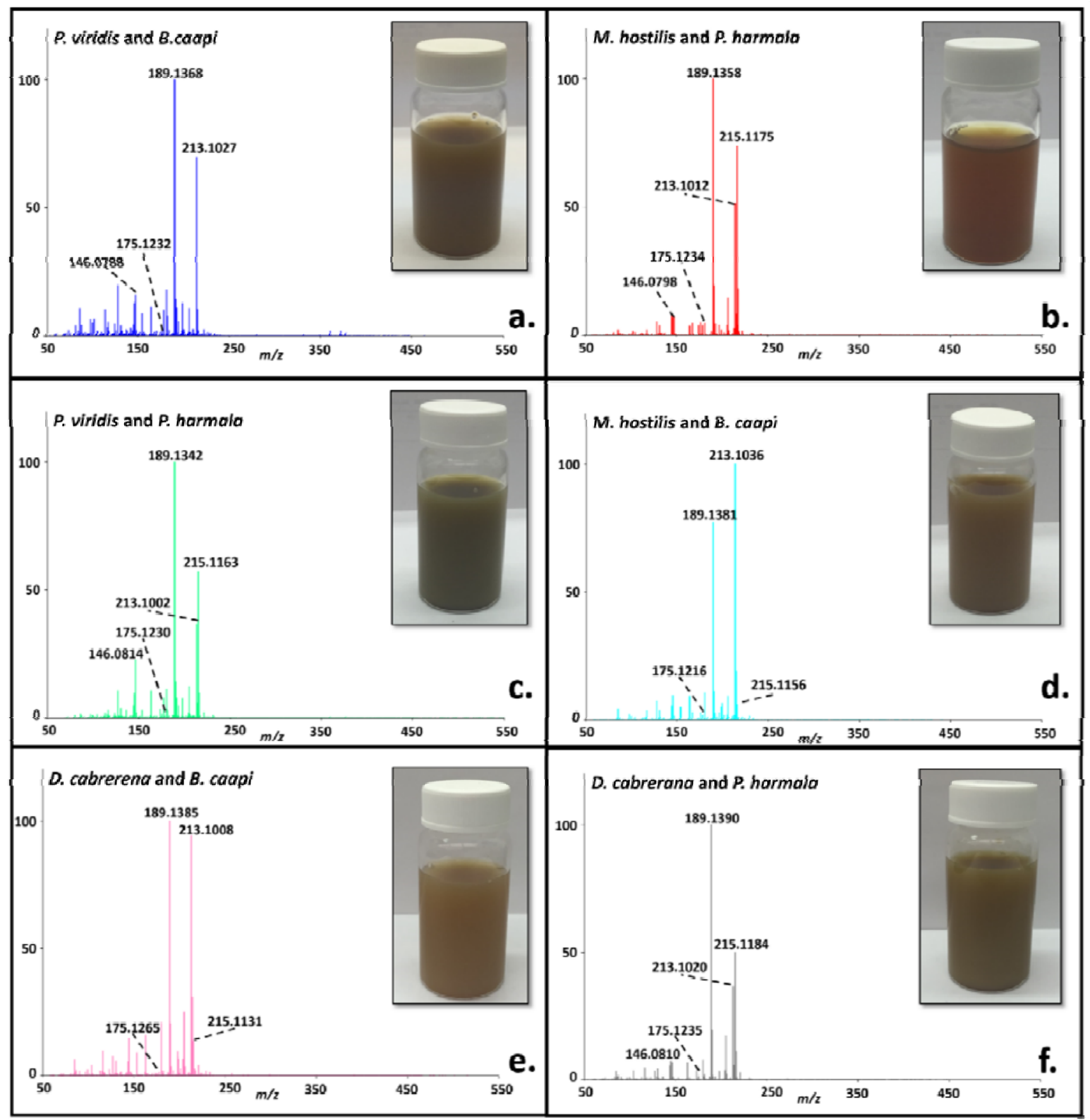

Figure 5: DART-HRMS soft ionization spectra of Ayahuasca brews. The inset in each Panel is an image of the brew that illustrates the subtle differences in their appearances. Panel a: $P$. viridis and B. caapi brew; Panel b: $P$. harmala and $M$. hostilis brew; Panel $\mathrm{c}$ : $P$. viridis and $P$. harmala brew; Panel $\mathrm{d}$ : $M$. hostilis and $B$. caapi brew; Panel e: D. cabrerana and B. caapi brew; Panel f: $D$. cabrerana and $P$. harmala brew. The mass measurement data associated with these spectra are shown in Table S-9. 
In previous studies, multivariate statistical analysis methods were applied to DART-

HRMS derived data to differentiate species and cultivars of plant-derived samples.[9, 10, 45] In these cases, the DART-HRMS spectra were visually very different, making it clear that multivariate statistical analysis approaches would be successful in distinguishing species. However, despite being comprised of different constituents, the spectra of the various Ayahuasca brews were remarkably similar. This is illustrated by the heat map rendering of the data, which represents a total of 900 individual analyses (Figure 6). High intensity peaks are dark red in color

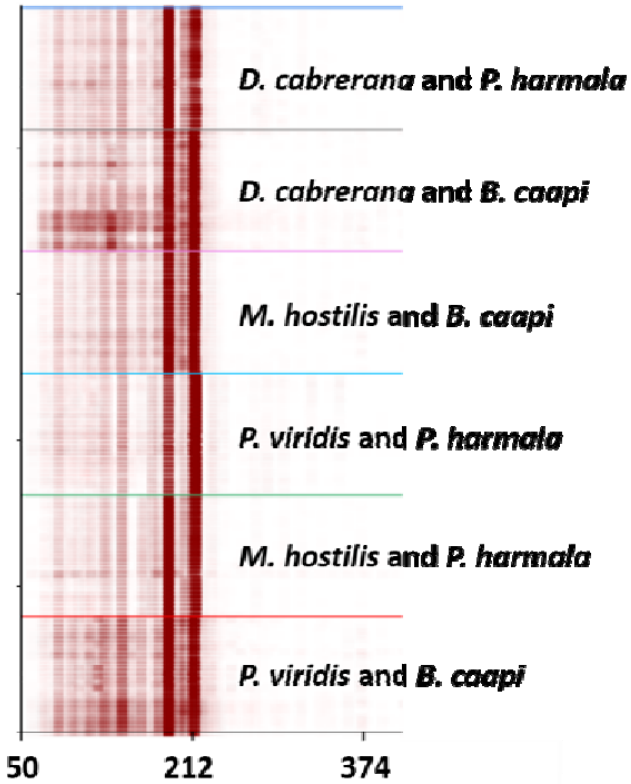

Figure 6. Heat map renderings of the DART-HRMS spectra of Ayahuasca brews. High intensity peaks are shown in dark red and lower intensity peaks are indicated by lighter shades.

and lower intensity peaks appear in lighter shades. Visually, there are few differences within each class, despite analysis of different fractions, and also between the different classes of brews, as the highest intensity peaks are at $m / z 189,213$, and 215 representing DMT, harmine and harmaline, respectively.

Therefore, principal component analysis (PCA) was applied to the dataset to determine if the botanical species of origin from which each brew was comprised could be determined. Using five feature masses (Table 3), a PCA plot was generated using three principal components (Figure 7). Each brew is represented by thirty data points: brew 1

Table 3. Feature masses used for principal component analysis (PCA) of Ayahuasca brews. The PCA plot is shown in Figure 5.

\begin{tabular}{|c|c|}
\hline 146.0788 & 213.1006 \\
\hline 189.1351 & 215.1170 \\
\hline 195.0874 & - \\
\hline
\end{tabular}

by blue circles, brew 2 by red squares, brew 3 by green triangles, brew 4 by turquoise circles, 
brew 5 by pink squares, and brew 6 by grey triangles. Each of the brews clustered independently, clearly reflecting differences between brews that were a function of the botanical components in the mixture. Data points with a low score along PC1 (x-axis) contain $P$. harmala as the $\beta$-carboline contributing plant, while data with a high PC1 score contain B. caapi as the harmala alkaloid contributing plant. With regard to the DMT-containing plant contributions, data points with a high PC2 value (y-axis) contain $P$. viridis as the DMT contributor, while data points with low PC2 scores indicate M. hostilis. Intermediate PC2 values arise from D. cabrerana contributions. Three principal components accounted for $86.38 \%$ of the

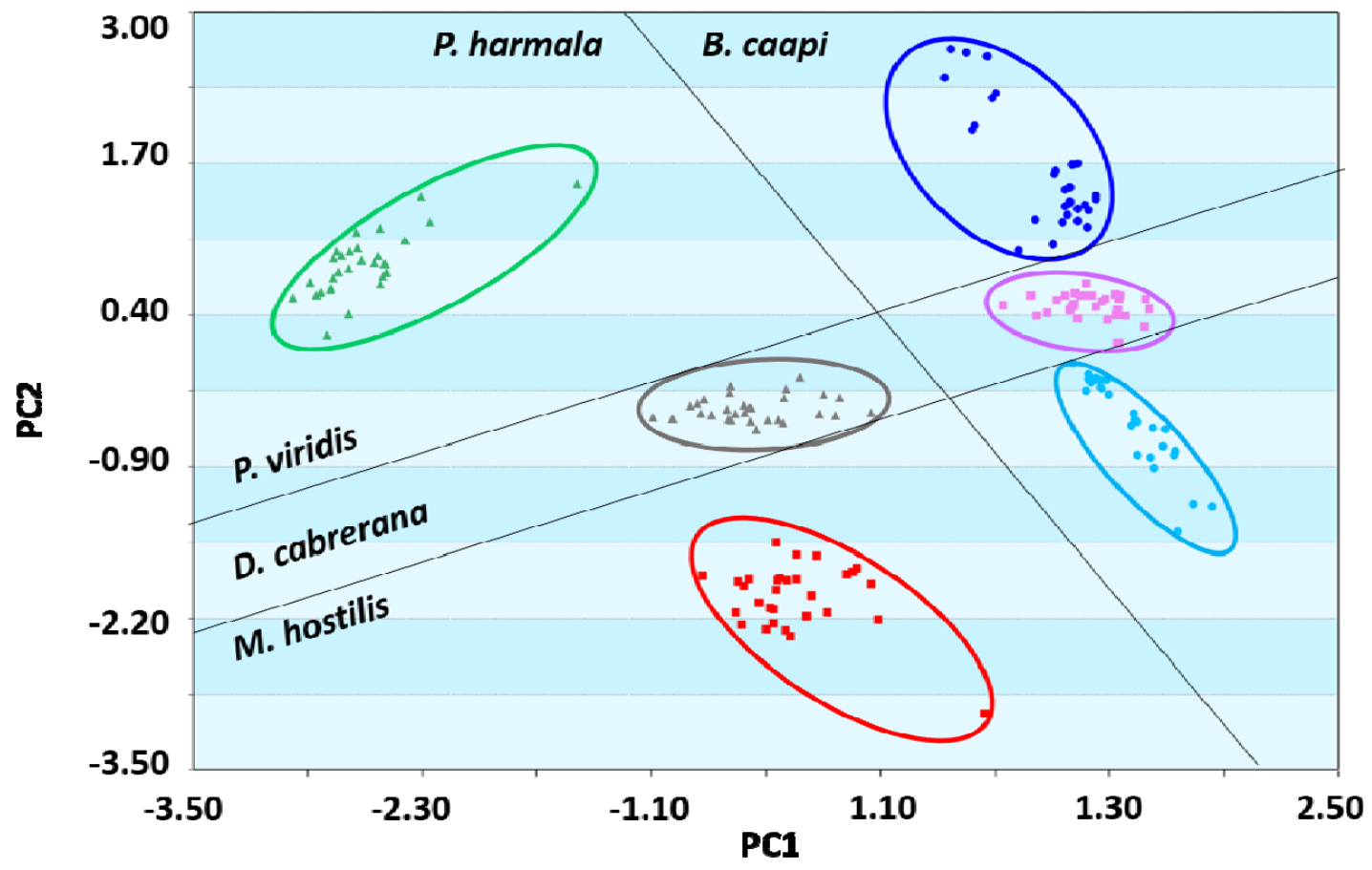
P. viridis and B. caapi
M. hostilis and B. caapi
M. hostilis and $P$. harmala
D. cabrerana and B. caapi
P. viridis and P. harmala
D. cabrerana and P. harmala

Figure 7. Principal component analysis (PCA) plot of six Ayahuasca brews constructed using DART-HRMS derived data. Mass spectral data with a low score along PC1 (x-axis) contain $P$. harmala as the $\beta$-carboline contributing plant, while data with a high PC1 score contain B. caapi as the harmala alkaloid contributing plant. Data points with a high PC2 value (y-axis) contain $P$. viridis as the DMT contributor, while data points with low PC2 scores indicate $M$. hostilis. Intermediate PC2 values arise from $D$. cabrerana contributions. Three principal components (PCs) accounted for $86.38 \%$ of the variation, and the leave-one-out cross validation (LOOCV) was $98.88 \%$. The feature masses used for the PCA are listed in Table 3. 
variance, and leave-one-out cross validation for the training set was $98.88 \%$.

\section{DISCUSSION}

The ability to identify new psychoactive substances (NPS), especially those in complex matrices, is increasingly important because of the rise in use of alternative drugs of abuse that are marketed and sold to circumvent current drug laws. Plant-based drugs are an NPS subset which, second to ketamine, are the largest group of NPSs emerging on the drug market worldwide.[47] Of the 20 plant-based drugs of concern listed in the UNODC bulletin, four are used in the creation of Ayahuasca brews. Thus, the need to identify these psychoactive materials as well as mixtures or brews made from them will become increasingly necessary, as the sale of the products grows due to their legal status around the world.

There are few published protocols for the identification of the psychoactive components in Ayahuasca brews found as evidence at a crime scene or submitted to forensic drug chemistry laboratories. GC-MS protocols have been developed for the characterization of Ayahuasca brews, $[37,39,40]$ but the sample preparation steps and long chromatographic programs makes routine screening and identification challenging, especially in light of casework backlogs.[42] LC-MS methodology would enable analysis of aqueous Ayahuasca brews to be more straightforward than would be required for GC-MS. Yet, reports of such methods are absent in the literature, particularly regarding identification of Ayahuasca brews and the individual components of psychoactive plant material mixtures. Furthermore, although LC-MS protocols have been developed for identification of DMT and harmala alkaloids in human 
biological samples including serum, plasma and blood $[2,18,48]$, there are no reports for identification of Ayahuasca itself in an evidentiary context. Characterization of the specific plant materials used in Ayahuasca preparations (as opposed to the brew itself) has been achieved using LC-MS methodology.[49] However, the lengthy sample preparation steps, intensive method development and long chromatographic run times make this an impractical solution for routine analysis.

The approach described here provides a means to rapidly triage forensic sample unknowns and determine whether or not they are Ayahuasca. Specifically, we show that by chemometric processing of DART-HRMS data, it is possible to not only identify the concoctions as Ayahuasca, but also that: (1) the presence of psychoactive constituents could be confirmed without the need for extensive sample preparation steps; and (2) the plant species of which the brews were comprised could be determined. DMT and $N$-methyltryptamine were both detected in $P$. viridis, $M$. hostilis, and $D$. cabrerana. This observation is consistent with the results of previous reports, $[23,25,28-30]$ and supports the use of these plant materials as the main contributors to the hallucinogenic effects in Ayahuasca beverages (Figure 2). While the most abundant peak in the $P$. viridis, $M$. hostilis, and $D$. cabrerana samples represented DMT, the chemical fingerprint of each of the plant materials was unique between each species. Masses consistent with the harmala alkaloids harmol, harmine, harmaline, and tetrahydroharmine were detected in the $B$. caapi vine material, and deoxypeganine, vasicine, harmine, and harmaline were also tentatively identified in the $P$. harmala seeds. Despite being detected in both species, harmine and harmaline were present in different relative intensities, with $B$. caapi presenting a higher abundance of harmine, and $P$. harmala exhibiting a higher relative intensity 
of harmaline. The use of in-source collision-induced dissociation provided confirmation of the tentative assignments of the psychoactive compounds in the plant materials. DMT was confirmed to be present in $P$. viridis, M. hostilis and D. cabrerana by comparison of the $60 \mathrm{~V}$ spectra of the plant material to the $60 \mathrm{~V}$ spectrum of the DMT standard. Harmine and harmaline were confirmed to be present in both B. caapi and P. harmala through in-source CID comparisons of the $90 \mathrm{~V}$ spectra the plant material and the standards, and vasicine was also identified in the $P$. harmala seeds in the same manner.

Differences in the chemical fingerprints of the plant species in Ayahuasca brews indicated that the use of different plant combinations would slightly alter the overall composition of the brew. Therefore, in principle, the identity of the species of plants used in the beverages could be determined based on the unique chemical fingerprints of the brews. To investigate this hypothesis, six Ayahuasca brews were prepared from various pairings of DMT and harmala alkaloid-containing botanical materials (Figure 5). In each case, DMT was readily detected at nominal $m / z 189$, as were harmine and harmaline at $m / z 213$ and 215 respectively, indicating that the brews were in fact Ayahuasca. Visually, the mass spectral profiles of the brews were remarkably similar, (Figure 6), but based on the differences in the chemical compositions of the botanical species used in the brews, the identification of species used in the mixtures was explored through statistical analysis processing.

Due to the time required for a single GC- or LC-MS analysis, generation of the voluminous chromatographic data required for the application of statistical analysis methods is not practical. However, the rapidity of DART-HRMS analysis permits the rapid acquisition of large datasets required for the application of statistical analysis methods to the spectral data. 
Here, PCA was applied to the Ayahuasca brew fingerprints to determine if the species identity of the plant materials used in the brew could be verified. The PCA plot generated (Figure 7) showed clear distinctions with no overlap between each of the six brews, as well as tight clustering within each class. Moreover, there were distinctions along PC1 between brews that contained B. caapi as the harmala alkaloid contributor to the Ayahuasca beverage, and those that contained $P$. harmala as the source of harmala alkaloids. Similarly, there were distinctions between each of the brews as a function of the DMT-containing plant used in the concoction. Along PC 2, data points with higher values are those of $P$. viridis, those with intermediate values align with $D$. cabrerana, and those with low PC 2 values contain $M$. hostilis as the hallucinogen contributor.

Three principal components (derived from the five selected feature masses) accounted for $86.38 \%$ of the observed variance in the PCA plot. The feature masses were associated specifically with the psychoactive compounds present in the plant materials used in making Ayahuasca. The inclusion of additional feature masses was unnecessary for validation of the statistical analysis method, as they did not contribute substantially to the variance. Thus, the leave-one-out cross validation was found to be $98.88 \%$. The use of statistical analysis processing on DART-HRMS data enabled a level of certainty to be associated with the identity of the composition of the brew, an outcome the accomplishment of which has been emphasized as highly desirable by the National Academy of Sciences.[35] Moreover, the successful classification by botanical species in this way could provide law enforcement with vendor or manufacturer information that might be essential in sourcing the product. 


\section{CONLCUSION}

DART-HRMS analysis of Ayahuasca beverages revealed unique chemical fingerprints based on the characteristic signatures of the psychoactive botanical species used in the making of the brews. In-source CID confirmed the presence of the hallucinogen DMT in $P$. viridis leaves, $M$. hostilis root bark, and $D$. cabrerana leaves, and various harmala alkaloids in $B$. caapi and $P$. harmala. The detection of DMT in conjunction with the presence of harmine and harmaline enabled identification of the brews as Ayahuasca. Moreover, PCA revealed that while the spectra of the mixtures were visually similar, the composite of constituents in the six brews were unique enough to enable differentiation of the specific combination of plant species used in the making each Ayahuasca beverage. This definitive classification is not possible if currently used conventional methods that simply rely on confirmation of the presence of DMT, are used. The method described herein can be readily applied to a variety of compounded plant-based products, in a manner that circumvents time- and resource intensive sample preparation steps. Furthermore, it could provide a means for forensic laboratories and emergency medical staff to rapidly and accurately identify abused substances.

\section{REFERENCES}

[1] Neerman M, Frost R, Deking J. A drug fatality involving Kratom. J Forensic Sci. 2013;58:S28-S279. [2] Sklerov J, Levine B, Moore KA, King T, Fowler D. A fatal intoxication following the ingestion of 5methoxy-N,N-dimethyltryptamine in an ayahuasca preparation. J Anal Toxicol. 2005;29:838-41.

[3] Kronstrand R, Roman M, Thelander G, Eriksson A. Unintentional fatal intoxications with mitragynine and o-desmethyltramadol from the herbal blend Krypton. J Anal Toxicol. 2011;35:242-7. 
[4] Lystra T. Coroner: Role of kratom in Longview mom's death undetermined.

http://tdn.com/news/local/coroner-role-of-kratom-in-longview-mom-s-deathundetermined/article 0822689c-b74e-11e2-a636-0019bb2963f4.html. December 18, 2013.

[5] Holler J, Vorce S, McDonough-Bender P, Jr. JM, Soloman C, Levine B. A drug toxicity death involving proylhexedrine and mitragynine. J Anal Toxicol. 2011;35.

[6] Escobedo T. Teen's quest for Amazon 'medicine' ends in tragedy.

http://www.cnn.com/2014/10/24/justice/ayahuasca-death-kyle-nolan-mother/. 12.1.2015.

[7] Diker D, Markovitz, D., Rothman, M., Sendovski, U. Coma as a presenting sign of Datura stramonium seed tea poisoning. Eur J Intern Med. 2007;18:226-8.

[8] Russell J, Edwards, C., Jordan, C., Luckman, E., Chu, A., Blythe, D. , Krick J. Jimsonweed poisoning associated with a homemade stew- Maryland, 2008. Morbidity and Mortality Weekly Report: Center for Disease Control; 2010. p. 102-3.

[9] Lesiak AD, Cody RB, Dane AJ, Musah RA. Plant seed species identification from chemical fingerprints: a high-throughput application of direct analysis in real time mass spectrometry. Anal Chem. 2015;87:8748-57.

[10] Lesiak AD, Cody RB, Dane AJ, Musah RA. Rapid detection by direct analysis in real time-mass spectrometry (DART-MS) of psychoactive plant drugs of abuse: The case of Mitragyna speciosa aka "Kratom". Forensic Sci Int. 2014;242:210-8.

[11] Tupper KW, Labate BC. Ayahuasca, psychedelic studies and health sciences: the politics of knowledge and inquiry into an Amazonian plant brew. Curr Drug Abuse Rev. 2014;7:71-80.

[12] Laurent R, Jan-Erik L. "Ayahuasca," the South American hallucinogenic drink: an ethnobotanical and chemical investigation. Econ Botany. 1972;26:101-29.

[13] Freedland CS, Mansbach RS. Behavioral profile of constituents in ayahuasca, an Amazonian psychoactive plant mixture. Drug Alcohol Depend. 1999;54:183-94.

[14] McKenna DJ. Clinical investigations of the therapeutic potential of ayahuasca: rationale and regulatory challenges. Pharmacol Therap. 2004;102:111-29.

[15] Kjellgren A, Eriksson A, Norlander T. Experiences of encounters with ayahuasca--"the vine of the soul". J Psychoactive Drug. 2009;41:309-15.

[16] Gable RS. Risk assessment of ritual use of oral dimethyltryptamine (DMT) and harmala alkaloids. Addiction. 2007;102:24-34.

[17] American Found Dead After Taking Ayahuasca. Peruvian Times;

http://www.peruviantimes.com/14/american-found-dead-after-taking-ayahuasca/16785/. 12.1.2015.

[18] Frison G, Favretto D, Zancanaro F, Fazzin G, Ferrara SD. A case of beta-carboline alkaloid intoxication following ingestion of Peganum harmala seed extract. Forensic Sci Int. 2008;179:e37-43.

[19] McVeigh T. British backpacker dies after taking hallucinogenic brew in Colombia. The Guardian;

http://www.theguardian.com/uk-news/2014/apr/27/british-backpacker-dies-hallucinogenic-drugcolombia. 12.1.2015.

[20] Man appears in court after police seize hallucinogenic drugs.

http://www.westernmorningnews.co.uk/Man-appears-court-police-seize-hallucinogenic-drugs/story-

11725432-detail/story.html.

[21] Lloyd J, Guinyard T. DMT Drug Lab Found in Apartment After Officers Encounter Screaming, Naked Man; http://www.nbclosangeles.com/news/local/Sherman-Way-Drug-Lab-Bust-Arrest-LAPD--

264222391.html. 12.22.2015.

[22] Daetz A. Mountain View Police Bust Up DMT Drug Lab. http://abc7news.com/archive/8879485/.

[23] Callaway JC, Brito GS, Neves ES. Phytochemical analyses of Banisteriopsis caapi and Psychotria viridis. J Psychoactive Drug. 2005;37:145-50.

[24] Thies TA. Legally Stoned: 14 Mind Altering You Can Obtain and Use Without Breaking the Law: Citadel; 2008. 
[25] McKenna DJ, Towers GH, Abbott F. Monoamine oxidase inhibitors in South American hallucinogenic plants: tryptamine and beta-carboline constituents of ayahuasca. J Ethnopharmacol. 1984;10:195-223.

[26] Mcllhenny EH, Pipkin KE, Standish L, Wechkin HA, Strassman R, Barker SA. Direct analysis of psychoactive tryptamine and harmala alkaloids in the Amazonian botanical medicine ayahuasca by liquid chromatography-electrospray ionization-tandem mass spectrometry. J Chromatogr A. 2009;1216:8960-

8.

[27] Zhao T, Zheng SS, Zhang BF, Li YY, Bligh SW, Wang CH, et al. Metabolic pathways of the psychotropic-carboline alkaloids, harmaline and harmine, by liquid chromatography/mass spectrometry and NMR spectroscopy. Food Chem. 2012;134:1096-105.

[28] Riba J, Mcllhenny EH, Valle M, Bouso JC, Barker SA. Metabolism and disposition of N,Ndimethyltryptamine and harmala alkaloids after oral administration of ayahuasca. Drug Test Anal. 2012;4:610-6.

[29] Samoylenko V, Rahman MM, Tekwani BL, Tripathi LM, Wang YH, Khan SI, et al. Banisteriopsis caapi, a unique combination of MAO inhibitory and antioxidative constituents for the activities relevant to neurodegenerative disorders and Parkinson's disease. J Ethnopharmacol. 2010;127:357-67.

[30] Gambelunghe C, Aroni K, Rossi R, Moretti L, Bacci M. Identification of N,N-dimethyltryptamine and beta-carbolines in psychotropic ayahuasca beverage. Biomed Chromatogr. 2008;22:1056-9.

[31] Tittarelli R, Mannocchi G, Pantano F, Romolo FS. Recreational use, analysis and toxicity of tryptamines. Curr Neuropharmacol. 2015;13:26-46.

[32] US Drug Enforcement Administration. N,N-Dimethyltryptamine (DMT). http://www.deadiversion.usdoj.gov/drug_chem_info/dmt.pdf. 2013.

[33] US Drug Enforcement Administration. Schedules of Controlled Substances.

http://www.deadiversion.usdoj.gov/21cfr/cfr/1308/1308 11.htm. 12.7.2015.

[34] FINAL ACT OF THE UNITED NATIONS CONFERENCE FOR THE ADOPTION OF A PROTOCOL ON PSYCHOTROPIC SUBSTANCES. https://www.unodc.org/pdf/convention 1971 en.pdf.

[35] Strengthening Forensic Science in the United States: A Path Forward. Committee on Identifying the Needs of the Forensic Sciences Community, National Research Council; 2009.

[36] Callaway JC. Various alkaloid profiles in decoctions of Banisteriopsis caapi. J Psychoactive Drug. 2005;37:151-5.

[37] Casale JF, Koles JE. Analysis of Ayahuasca ("Santo Daime"). Microgram. 1995;28:296-99.

[38] Gaujac A, Dempster N, Navickiene S, Brandt SD, de Andrade JB. Determination of N,Ndimethyltryptamine in beverages consumed in religious practices by headspace solid-phase microextraction followed by gas chromatography ion trap mass spectrometry. Talanta. 2013;106:394-8. [39] Gaujac A, Aquino A, Navickiene S, de Andrade JB. Determination of N,N-dimethyltryptamine in Mimosa tenuiflora inner barks by matrix solid-phase dispersion procedure and GC-MS. J Chromatogr B. 2012;881-882:107-10.

[40] Kikura-Hanajiri R, Hayashi M, Saisho K, Goda Y. Simultaneous determination of nineteen hallucinogenic tryptamines/beta-calbolines and phenethylamines using gas chromatography-mass spectrometry and liquid chromatography-electrospray ionisation-mass spectrometry. J Chromatogr B. 2005;825:29-37.

[41] Gaujac A, Navickiene S, Collins MI, Brandt SD, de Andrade JB. Analytical techniques for the determination of tryptamines and $\beta$-carbolines in plant matrices and in psychoactive beverages consumed during religious ceremonies and neo-shamanic urban practices. Drug Test Anal. 2012;4:63648.

[42] Walter A. Backlog delays evidence processing at state crime labs. The News and Advance. 2014. 6.09.2015.

[43] Cody R. Observation of molecular ions and analysis of nonpolar compounds with the Direct Analysis in Real Time ion source. Anal Chem. 2009;81:1101-7. 
[44] Cody R, Laramee J, Durst HD. Versatile new ion source for the analysis of materials in open air under ambient conditions. Anal Chem. 2005;77:2297-302.

[45] Musah RA, Espinoza EO, Cody RB, Lesiak AD, Christensen ED, Moore HE, et al. A high throughput ambient mass spectrometric approach to species identification and classification from chemical fingerprint signatures. Sci Rep. 2015;5.

[46] Pires AP, De Oliveira CD, Moura S, Dorr FA, Silva WA, Yonamine M. Gas chromatographic analysis of dimethyltryptamine and beta-carboline alkaloids in ayahuasca, an Amazonian psychoactive plant beverage. Phytochem Anal. 2009;20:149-53.

[47] The challenge of new psychoactive substances. UNODC;

http://www.unodc.org/documents/scientific/NPS 2013 SMART.pdf.

[48] Oliveira CD, Okai GG, da Costa JL, de Almeida RM, Oliveira-Silva D, Yonamine M. Determination of dimethyltryptamine and beta-carbolines (ayahuasca alkaloids) in plasma samples by LC-MS/MS. Bioanal. 2012;4:1731-8.

[49] Queiroz MM, Marti G, Queiroz EF, Marcourt L, Castro-Gamboa I, Bolzani VS, et al. LC-MS/MS quantitative determination of Tetrapterys mucronata alkaloids, a plant occasionally used in ayahuasca preparation. Phytochem Anal. 2015;26:183-8. 


\section{Graphical Abstract}

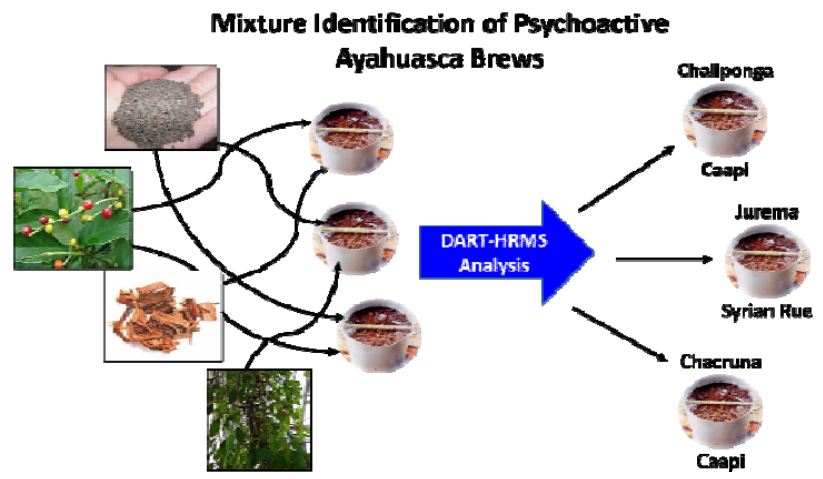

